\title{
DONATIEN ALPHONSE FRANÇOIS DE SADE, Voyage d'Italie
}

\section{Vittorio Fortunati}

\section{OpenEdition \\ Journals}

\section{Edizione digitale}

URL: https://journals.openedition.org/studifrancesi/31783

DOI: $10.4000 /$ studifrancesi.31783

ISSN: 2427-5856

\section{Editore}

Rosenberg \& Sellier

\section{Edizione cartacea}

Data di pubblicazione: 1 août 2020

Paginazione: 406-407

ISSN: 0039-2944

\section{Notizia bibliografica digitale}

Vittorio Fortunati, «Donatien alphonse françoIs de SADE, Voyage d'Italie», Studi Francesi [Online], 191 (LXIV I

II) | 2020, online dal 01 septembre 2020, consultato il 16 septembre 2021. URL: http://

journals.openedition.org/studifrancesi/31783 ; DOI: https://doi.org/10.4000/studifrancesi.31783

Questo documento è stato generato automaticamente il 16 septembre 2021.

\section{(c)}

Studi Francesi è distribuita con Licenza Creative Commons Attribuzione - Non commerciale - Non opere derivate 4.0 Internazionale. 


\title{
DONATIEN ALPHONSE FRANÇOIS DE SADE, Voyage d'Italie
}

\author{
Vittorio Fortunati
}

\section{NOTIZIA}

DONATIEN ALPHONSE FRANÇOIS DE SADE, Voyage d'Italie, édition établie et commentée par M.

Delon, Paris, Flammarion, 2019, 308 pp.

1 Nel luglio del 1775 il marchese de Sade lasciò la Francia attraverso il valico del Monginevro, per sottrarsi a un processo che lo vedeva imputato di sevizie ai danni di due adolescenti. Assunta la falsa identità di conte di Mazan, Sade percorse rapidamente l'Italia settentrionale per raggiungere Firenze, dove restò circa tre mesi, prima di portarsi a Roma. Trasferitosi a Napoli alla fine dello stesso anno, nel maggio del 1776 venne identificato e dovette rassegnarsi al ritorno in patria e all'arresto. $\mathrm{Fu}$ in prigione che Sade, utilizzando gli appunti raccolti nei mesi precedenti, cominciò la redazione del suo Voyage d'Italie, per il quale, seguendo un modello molto diffuso all'epoca (pensiamo alle Lettres familières del Président de Brosses), scelse la forma epistolare: le sue descrizioni della Penisola sono, infatti, rivolte a una innominata marchesa, nella quale si può riconoscere la moglie dell'autore. L'opera fu in seguito ripresa più volte, anche a distanza di molti anni, ma non fu mai pubblicata. Parte del suo contenuto fu, però, riutilizzato per narrare le avventure italiane di Juliette, sorella dell'infelice Justine e protagonista delle Prosperités du vice (1797). In effetti, alcuni dei temi e dei motivi più tipici dell'opera di Sade compaiono con una certa evidenza in diversi passi del suo Voyage. Si nota, per esempio, un gusto spiccato per la descrizione di situazioni scabrose (se non decisamente perverse), malcelato dietro a un tono di riprovazione, sia nelle pagine dedicate ai costumi italiani dell'epoca, sia in quelle di argomento storico o artistico. Più esplicita è l'ostilità del philosophe nei confronti della Chiesa cattolica, di cui sono condannate l'ingerenza politica, la corruzione, la responsabilità rispetto all'ignoranza e alla superstizione dei ceti popolari (esemplari al riguardo sono le pagine relative al miracolo del sangue di San Gennaro). Infine, il marchese dà prova del 
proprio cinismo laddove, in nome del progresso della scienza medica, si dichiara favorevole agli esperimenti su persone vive, precisando che le esistenze da sacrificare dovranno essere quelle, a suo dire inutili, di popolani e bifolchi. L'importanza del Voyage d'Italie nella carriera letteraria di Sade è messa bene in luce nella stimolante Préface di Michel Delon (pp. 7-41): questo "Grand Tour per necessità" coincise, infatti, per il marchese con la decisione di diventare scrittore e di trasformare in gloria letteraria la pessima nomea che gli era derivata da una condotta immorale. Questa edizione è arricchita da 32 riproduzioni fotografiche dei quaderni che contengono il manoscritto dell'opera e da alcuni disegni di Jean-Baptiste Tierce, un artista originario di Rouen che accompagnò Sade nelle sue escursioni nei dintorni di Napoli. 